WellBeing International

WBI Studies Repository

7-15-2007

\title{
The veterinary profession's duty of care in response to disasters and food animal emergencies
}

\author{
Kenneth E. Nusbaum \\ Auburn University \\ Bernard E. Rollin \\ Colorado State University - Fort Collins, bernard.rollin@colostate.edu \\ James S. Wohl \\ Auburn University
}

Follow this and additional works at: https://www.wellbeingintlstudiesrepository.org/proveth

Part of the Animal Studies Commons, Bioethics and Medical Ethics Commons, and the Other Veterinary Medicine Commons

\section{Recommended Citation}

Nusbaum, K. E., Rollin, B. E., \& Wohl, J. S. (2007). The veterinary profession's duty of care in response to disasters and food animal emergencies. Journal of the American Veterinary Medical Association, 231(2), 200-202. https://doi.org/10.2460/javma.231.2.200

This material is brought to you for free and open access by WellBeing International. It has been accepted for inclusion by an authorized administrator of the WBI Studies Repository. For more information, please contact wbisr-info@wellbeingintl.org.

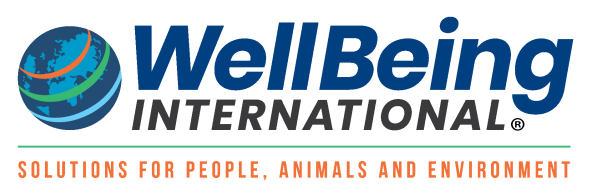




\title{
Commentary
}

\section{The veterinary profession's duty of care in response to disasters and food animal emergencies}

\author{
Kenneth E. Nusbaum, DVM, PhD, DACvM; Bernard E. Rollin, PhD; \\ James S. Wohl, DVM, MPA, DACVIM, DACVECC
}

$T_{s}$ he issue of public health and veterinary emergency response has persisted from the 2001 outbreak of footand-mouth disease in the United Kingdom through the anthrax-laced letters of September 2001 and the 2002-2003 outbreak of exotic Newcastle disease in California. These have been reinforced by the threat of pandemic avian influenza and the pet strandings during hurricanes Katrina and Rita in 2005. $\cdot^{1-4}$ Although veterinary medical assistance teams have been established and deployed in the United States, the question of large and small animal practitioner involvement in emergency response still hangs over the profession. What, if any, is our obligation to participate in response to epidemic disease during state, regional, or national disasters? From where does that obligation arise? What are obstacles to and benefits of participation?

In 2006, Daniel K. Sokol raised the topic of the challenge and conflicts of the duty of care for human health care workers in the context of potentially fatal pandemic infections. His exploration of the problem included specifying the roles of physicians and nursing supervisors in providing appropriate information to health care staff to permit sufficient personal protection to sustain health. He also recognized the duty of health care personnel to protect their own lives even when treating patients infected with highly communicable agents and mentioned the reliance on good patients to be reasonable in demanding health care. Sokol concluded that insufficient discussion has occurred to develop well-delineated guides for the moral and professional conduct of care provided by health care workers treating people with highly contagious diseases.

So, too, veterinarians should consider their obligations to their patients and society in the event of public health emergencies. The question of participation is far more complex for veterinarians than for physicians. Because no precedent will likely exist for the roles that will open to US

From the Departments of Pathobiology (Nusbaum) and Clinical Sciences (Wohl), College of Veterinary Medicine, Auburn University, Auburn, AL 36849; and the Department of Philosophy, College of Liberal Arts, Colorado State University, Fort Collins, CO 80523 (Rollin).

Address correspondence to Dr. Nusbaum. veterinarians, decisions will be ad hoc for each individual (Figure 1). In veterinary medicine, we have rarely been confronted with the contradictory demands of public service and personal sacrifice; indeed, the Principles of Veterinary Medical Ethics of the American Veterinary Medical Association ${ }^{6}$ apply to normal times. Under normal circumstances, professional behavior can easily accommodate the following recommendations from those principles:

- Veterinarians should first consider the needs of the patient: to relieve disease, suffering, or disability while minimizing pain or fear.

- Veterinarians will choose whom they will serve.

- The responsibilities of the veterinary profession extend beyond individual patients and clients to society in general.

- The choice of treatments or animal care should not be influenced by considerations other than the needs of the patient, the welfare of the client, and the safety of the public.

People in the United States and the planet now live in interesting times, subject to threats of invasion of foreign animal diseases as natural events (eg, infectious

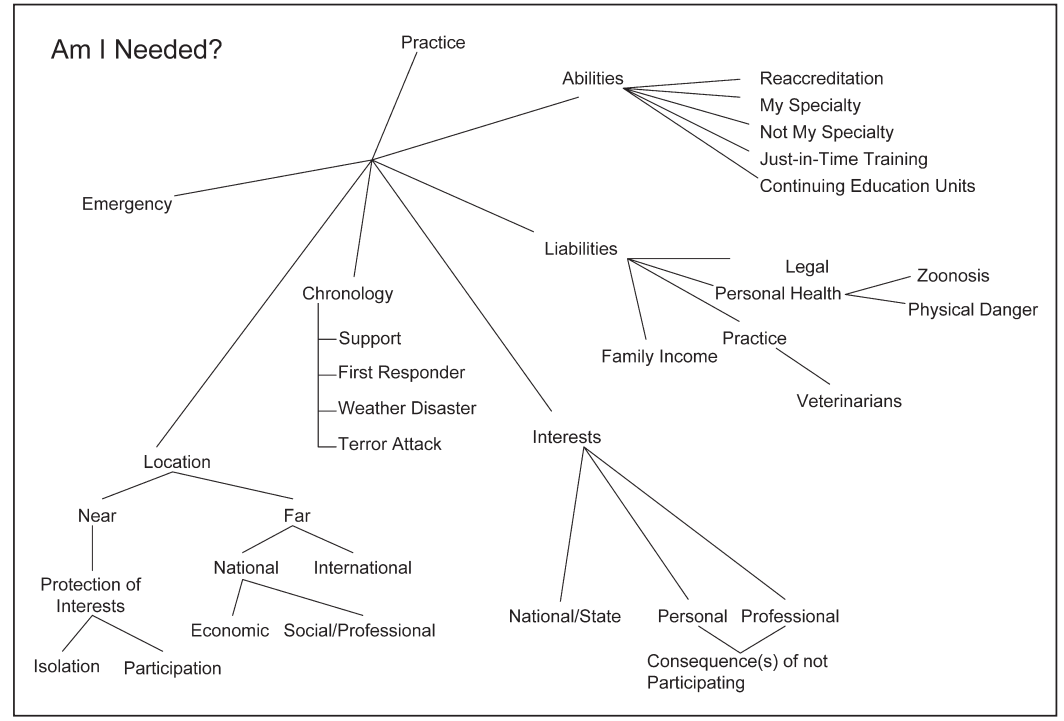

Figure 1-Decision tree for self-deployment in case of an animal disaster. In the absence of prior training and commitment for participation in the control of an animal disaster, the sequence of events and decisions leading to a decision is contradictory and ambiguous. 
salmon anemia and avian influenza) or accidents of commerce (eg, monkeypox and coronaviral severe acute respiratory syndrome) and terrorist attacks with agricultural, mostly nonzoonotic, agents or human pathogens of which approximately $95 \%$ are zoonotic. ${ }^{3,7-10}$

Veterinarians are struggling for recognition of their role in public health policy and national economic health as noted in a recent white paper prepared by the Association of American Veterinary Medical Colleges ${ }^{11}$; this effort was propelled by activities of veterinarians aiding stranded pets in the aftermath of Hurricane Katrina. By use of that nationally visible platform, the profession should increase its profile through increased abilities to ameliorate state and national animal disease crises; we should assume the duty to participate and examine the demands and questions that accompany such an increased role. The question that arises most quickly is parallel to Sokol's inquiry: what is the duty of the veterinary profession and the individual veterinarian to participate in operations that we might label extra practice or off-practice events that are unpredictable or even unimaginable?

Physicians, however, have a clear duty to participate in restoring human health, and that profession has well-developed supply chains that will bring personnel and supplies to them with a higher priority than veterinarians can hope to muster. And, physicians will be paid. In the end, however, professional responsibility accompanies professional status, and participation cannot be abandoned.

Although we lack precedent, we have had sufficient warnings to cause a higher state of professional situational awareness following recent meteorologic and epidemic events. In the absence of precedent, and we should hope not to have a precedent, veterinarians would be well-advised to develop a policy for emergency response. The basis for that policy is in the Veterinarian's Oath, “...for the benefit of society...the conservation of animal resources, the promotion of public health..."12 and the Principles of Veterinary Medical Ethics ${ }^{6}$ that states, "The responsibilities of the veterinary profession extend beyond individual patients and clients to society in general," and "The choice of treatments or animal care should not be influenced by considerations other than the needs of the patient, the welfare of the client, and the safety of the public."

Thus our duty to participate in animal disease emergencies is clear. However, we read of large impending retirements among federal veterinarians and of the unmet need for thousands of veterinarians in public health. Furthermore, the day of the good samaritan in disaster relief, when a veterinarian with a truck or a bag could show up at a disaster and announce willingness to help, is gone because of the emergence of the Incident Command System (ICS) as the national standard for managing events and disasters. ${ }^{13}$ Many states are developing sophisticated response plans for state or county agriculture response teams, which require training in the federal ICS, credentialing, or being issued photo identification and training specific for some aspect of emergency response. How will the veterinary profes- sion provide sufficient expertise to fulfill the needs generated by a national emergency?

Although progress is being made on the state level through the development of state or county agriculture response teams, ideally, some sort of national leadership would help galvanize and unify all veterinarians. The role of a policy for veterinary participation in a national animal disease emergency should validate the role of veterinarians in animal care and disease control in a disaster area; provide means for training veterinarians in ICS and emergency management of livestock, pets, volunteers, and disease; and reduce the consequence tree (Figure 1) into a checklist for participation (Appendix). A well-written policy should ultimately facilitate a predictable number of well-prepared and readily trainable veterinarians for mission response. In our opinion, this training should entail traditional lecture and distance-learning methods for the basic instruction and should provide access to traditional or distance just-in-time training specific to each new deployment. This would provide veterinarians with ongoing professional stimulation and an opportunity to explore or experience various aspects of the profession. The policy would enhance the image of veterinary medicine in the national mindset. In the short term, there seems to be no need for national standards of participation because so many states are moving forward with their own programs. However, we believe a policy promulgated at the national level would advance the program for all states and all practitioners.

Among the priorities would be the following:

- Enunciate the duty of care or participation for the veterinary profession when the nation confronts disasters and outbreaks of animal disease.

- Consider ICS training as part of continuing education for all licensed veterinarians to synchronize skills with state and national disaster plans.

- Coordinate or develop continuing education skill sets needed for response to various disasters (eg, hurricane, flood, tornado, and fire) or disease outbreaks (eg, livestock, pet, and zoonotic diseases).

- Develop skill sets to enroll food animal and companion animal practitioners in disaster response.

- Make professional participation in disaster preparedness part of a national public relations campaign.

\section{Appendix}

Checklist for disaster participation, requiring yes or no responses.

Absolute requirements for participation
- Have I chosen to participate?
- Have I taken ICS training?
- Have I taken other required background courses?
- Have I made arrangements with my practice to deploy?
Incident participation
- Have I been invited to participate?
- Are my skill sets a match for the mission?
- needed I access just-in-time training to refresh skills or acquire
- Is this a self-support mission?
Do I have supplies needed for three to five days of self-
support?




\section{References}

1. Musser JMB. A practitioner's primer on foot-and-mouth disease. J Am Vet Med Assoc 2004;224:1261-1268.

2. Warner RD. Promoting the veterinarian's role in public health J Am Vet Med Assoc 2002;220:740.

3. Swayne DE, King DJ. Avian influenza and Newcastle disease. J Am Vet Med Assoc 2003;222:1534-1540.

4. Beaver BV, Gros R, Bailey EM, et al. Report of the 2006 National Animal Disaster Summit. J Am Vet Med Assoc 2006;229:943-948.

5. Sokol DK. Virulent epidemics and scope of healthcare workers' duty of care. Emerg Infect Dis 2006;12:1238-1244.

6. AVMA. 2007 AVMA membership directory and resource manual. Schaumburg, Ill: AVMA, 2007;36-40.7.

7. Foreign animal disease alert: investigation uncovers first monkeypox infection in Western Hemisphere. Available at: www. avma.org/public_health/monkeypox/default.asp. Accessed Oct 5, 2006.

8. DiVita LJ. Maine imposes emergency rules regarding salmon virus. J Am Vet Med Assoc 2001;219:1335.

9. AVMA. Veterinarians the "first line of defense" in biologic attack. J Am Vet Med Assoc 2003;222:1334.

10. Noah DL, Noah DL, Crowder HR. Biological terrorism against animals and humans: a brief review and primer for action. J Am Vet Med Assoc 2002;221:40-43.

11. Kahler SC. White paper advises partnership to reverse veterinarian shortages. J Vet Med Assoc 2003;223:1404.

12. AVMA. 2007 AVMA membership directory and resource manual. Schaumburg, Ill: AVMA, 2007;349.

13. AVMA disaster preparedness and response guide. Available at: www.avma.org/disaster/responseguide/B_system.pdf. Accessed Oct 5, 2006. 